\title{
Mission and System Advantages of Iodine Hall Thrusters
}

\author{
John W. Dankanich ${ }^{1}$ \\ NASA Marshall Space Flight Center, MSFC, AL, 35812, U.S.A. \\ James Szabo ${ }^{2}$ and Bruce Pote ${ }^{3}$ \\ Busek Co. Inc., Natick, MA, 01760, U.S.A \\ and \\ Steve Oleson ${ }^{4}$ and Hani Kamhawi ${ }^{5}$ \\ NASA Glenn Research Center, Cleveland, OH 44135, U.S.A
}

\begin{abstract}
The exploration of alternative propellants for Hall thrusters continues to be of interest to the community. Investments have been made and continue for the maturation of iodine based Hall thrusters. Iodine testing has shown comparable performance to xenon. However, iodine has a higher storage density and resulting higher $\Delta V$ capability for volume constrained systems. Iodine's vapor pressure is low enough to permit low-pressure storage, but high enough to minimize potential adverse spacecraft-thruster interactions. The low vapor pressure also means that iodine does not condense inside the thruster at ordinary operating temperatures. Iodine is safe, it stores at sub-atmospheric pressure, and can be stored unregulated for years on end; whether on the ground or on orbit. Iodine fills a niche for both low power $(<1 \mathrm{~kW})$ and high power $(>10 \mathrm{~kW})$ electric propulsion regimes. A range of missions have been evaluated for direct comparison of Iodine and Xenon options. The results show advantages of iodine Hall systems for both small and microsatellite application and for very large exploration class missions.
\end{abstract}

\section{Introduction}

$\mathrm{H}^{2}$ all thrusters belong to the family of electric thrusters. Electric thrusters use electric energy to heat or ionize and accelerate the injected propellant. In comparison to chemical thrusters, electric thrusters offer a much higher specific impulse capability and thus dramatically reduce the amount of propellant needed to achieve a predetermined $\Delta \mathrm{V}$. A large number of flight Hall systems have been developed, flown and continue to fly in space.

Hall thrusters with xenon propellant have excellent mission performance at power levels from $1 \mathrm{~kW}-10 \mathrm{~kW}$. However, small satellites with severe volume constraints have limited potential for high pressure xenon systems. At high power, xenon Hall thrusters $>10 \mathrm{~kW}$ are pushing the limits of ground facility capabilities; with iodine, spacerelevant background pressures are much easier to achieve. Additionally, missions requiring large amounts of propellant can have system level advantages due to the higher propellant densities and low storage pressures.

Under the support of the USAF and NASA's Small Business Innovation Research (SBIR) program, Busek has been evaluating the performance of the BHT-200 flight thruster with iodine, collecting performance data for higher power iodine thrusters and maturing a $600 \mathrm{~W}$ iodine propulsion system. NASA continues its investment in iodine based Hall systems to capture two distinct mission niches, very low power small satellites and high power exploration class electric propulsion. Advantages of a condensable propellant extend beyond flight mission advantages, but also provides ground test advantages; especially at high flow rates. System qualification and demonstration at low power may offer a practical option for a relatively rapid infusion of this new technology and at a fraction of the cost of high power implementation.

\footnotetext{
${ }^{1}$ Mission Analyst, Technology Development and Transfer Office, ZP30, AIAA Associate Fellow.

${ }^{2}$ Chief Scientist, Hall Thrusters, AIAA Associate Fellow.

${ }^{3}$ Director, Hall Thruster, AIAA Member.

${ }^{4}$ COMPASS Lead, NASA Glenn Research Center.

${ }^{5}$ Research Engineer, Propulsion and Propellants Branch, AIAA Associate Fellow.
} 


\section{Iodine Propulsion Development Background and Status}

\section{A. Iodine versus Alternatives}

Busek has been leading the exploration of alternative propellants for Hall thrusters. Tests and analyses were completed for magnesium (Mg), zinc ( $\mathrm{Zn})$, iodine, and bismuth (Bi). All of the high density options show promise for higher $\Delta \mathrm{V}$ capability for volume constrained applications. With respect to xenon, magnesium and zinc have lower atomic mass, which allows high specific impulse for constant discharge voltage. Bismuth HET systems have been developed at Busek and elsewhere. ${ }^{1,2}$ Soviet era literature indicates thruster efficiencies much greater than $50 \%$ have been achieved. ${ }^{3}$ With iodine, performance is comparable with SOA xenon, as detailed below, although testing indicates iodine produces slightly higher thrust-to-power, which is desired for many mission applications.

When selecting the propellant for any mission, system level considerations like storage density, pressure, and required temperature should be taken into account. The required power for vaporization limits the applicability magnesium, zinc, and bismuth for small satellite power starved missions. For such spacecraft, the high storage density and high vapor pressure of iodine makes it a superior candidate. Propellant characteristics for selected alternative propellants are shown in Error! Reference source not found..

Table 1: State-of-the-art Xenon and alternative propellant properties.

\begin{tabular}{|c|c|c|c|c|}
\hline Propellant & Storage Density & Boiling Point, ${ }^{\circ} \mathrm{C}$ & Melting Point, ${ }^{\circ} \mathrm{C}$ & Vapor Pressure @ 20 ${ }^{\circ} \mathbf{C}$ \\
\hline Xe (SOA) & $1.6 \mathrm{~g} / \mathrm{cm}^{3}$ & $-108.1^{\circ} \mathrm{C}$ & $-111.8^{\circ} \mathrm{C}$ & Supercritical (>15MPa) \\
\hline Iodine & $4.9 \mathrm{~g} / \mathrm{cm}^{3}$ & $184.3^{\circ} \mathrm{C}$ & $113.7{ }^{\circ} \mathrm{C}$ & $40 \mathrm{~Pa}(0.0004 \mathrm{~atm})$ \\
\hline Bismuth & $9.8 \mathrm{~g} / \mathrm{cm}^{3}$ & $1,564{ }^{\circ} \mathrm{C}$ & $271.4{ }^{\circ} \mathrm{C}$ & Solid \\
\hline Magnesium & $1.74 \mathrm{~g} / \mathrm{cm}^{3}$ & $1,091^{\circ} \mathrm{C}$ & $650{ }^{\circ} \mathrm{C}$ & Solid \\
\hline
\end{tabular}

Iodine stores as a high density diatomic solid, $\mathrm{I}_{2}$, and sublimates at room temperature. Solid $\mathrm{I}_{2}$ has a density of 4.9-kg/l. At typical storage conditions, e.g. $14-\mathrm{MPa}$ and $50^{\circ} \mathrm{C}$, the stored density of $\mathrm{Xe}$ is $1.6-\mathrm{kg} / \mathrm{l}$. At the same conditions, $\mathrm{Kr}$ stores at $0.5-\mathrm{kg} / \mathrm{l}$. The density of $\mathrm{I}_{2}$ is compared to that of $\mathrm{Xe}, \mathrm{Kr}$ and other electric rocket propellants in Error! Reference source not found..

The market has established xenon fueled systems in the 1-9kW power range. Here there is limited justification to supplant incumbents with lower maturity technology. However, both the very small and very large satellite markets have limitations that may be overcome through the implementation of iodine. Small thrusters may be ideal for CubeSats or other small spacecraft where volume is at a premium. Large thrusters and clusters with high throughput requirements can offer system packaging and propellant storage. Also, higher power systems with high flow rates may offer ground test advantages over non-condensable propellants, and therefore mission margin reduction and flight performance risk reduction. Large system applications may include large orbital tugs and human exploration missions.

To illustrate the benefits of iodine, it is useful to compute the propellant volume for a high throughput mission. Consider a notional mission requiring 13t of

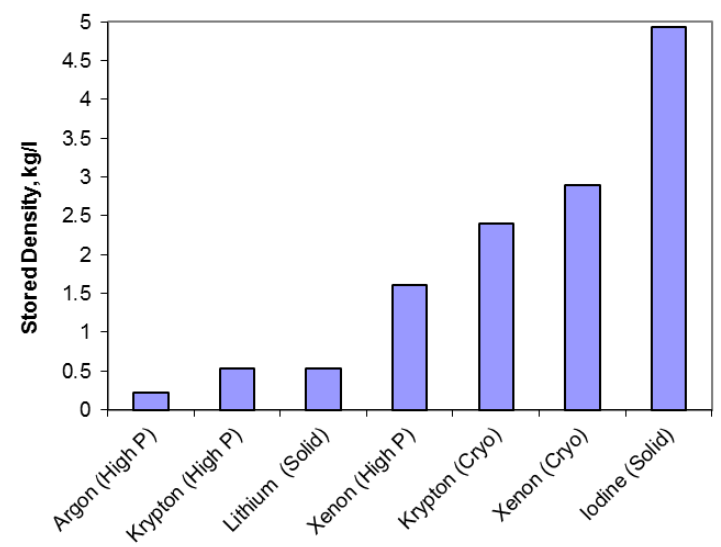

Figure 1. Stored Density of Electric Rocket Propellants in $\mathrm{kg} / \mathrm{l}$ (high pressure at $14-\mathrm{MPa}, 5^{\circ} \mathrm{C}$ ). propellant. At typical storage conditions, this implies 8,075-1 of high pressure Xe or 4,483-1 of cryogenic Xe (2.9-kg/l). With $\mathrm{I}_{2}$, the propellant volume could drop as low as 2,637-1. Furthermore, the $\mathrm{I}_{2}$ could be stored at low pressure and tanks not in use could be unregulated and quiescent without heating required and standard manufacturing techniques could be used for tank design and production. Finally, the low operating pressure also allows for conventional or potentially additive manufacturing of propellant tanks to nearly any desired shape without the need for domes or composites. 


\section{B. Performance and Plume Testing}

Busek first tested the BHT-200 $0^{4}$ with iodine under an Air Force sponsored program and presented results in $2011 .^{5}$ Busek subsequently tested the BHT $-1000^{6}$ and BHT- $-8000^{7}$ with iodine. All test data indicate that iodine performance is competitive with xenon performance at all power levels. The iodine operation typically trends to a higher thrust-to-power and slightly reduced specific impulse. Test results also indicate a reduction in plume divergence with iodine. ${ }^{6}$

Thrust is typically measure directly with an inverted pendulum, "Null" type thrust stand. ${ }^{8}$ Specific impulse is defined by

$$
I_{s p}=T / \dot{m} g_{0} .
$$

Here, $T$ is thrust, $\dot{m}$ is the total mass flow rate, and $g_{0}$ is the force of gravity the surface of Earth. When $I_{s p}$ is calculated using only the anode mass flow, $\dot{m}_{a}$, this is known as the anode $I_{s p}$. The efficiency determines the ratio of thrust to power $(T / P)$ available at a particular $I_{s p}$ through the relation

$$
\eta=\frac{T}{P} \frac{I_{s p} g_{0}}{2}
$$

Thus, at constant thruster efficiency there is a tradeoff between $(T / P)$ and $I_{s p}$. At constant voltage, a heavier propellant may yield lower $I_{s p}$ and higher $(T / P)$.

\section{1) BHT-200}

With iodine, a BHT-200 demonstrated a nominal anode efficiency of $48 \%{ }^{6}$ The thrust peaked at $25 \mathrm{mN}$ at a discharge power of $500 \mathrm{~W}$, and performed at $12-14 \mathrm{mN}$ under the nominal $200 \mathrm{~W}$ operation. A thrust-to-discharge power ratio of $75 \mathrm{mN} / \mathrm{kW}$ was demonstrated with $150 \mathrm{~V}$ discharge and $65 \mathrm{mN} / \mathrm{kW}$ under nominal conditions. The specific impulse under nominal conditions was approximately 1500 s, although the thruster demonstrated more than $2000 \mathrm{~s}_{\mathrm{SP}}$ with a $400 \mathrm{~V}$ discharge. The thrust and specific impulse demonstrated at various conditions is provided in Figure 2.

In addition to performance characterization, the iodine plume of the BHT-200 was evaluated for comparison to xenon. Faraday probe measurements of current density $j(\theta)$ showed lower plume divergence with iodine and the strong presence of diatomic ions in the plume. ${ }^{9}$ With an experimental version of the BHT-200, the dimer population was found to vary with thruster operating conditions and angular position with respect to the thruster centroid. With the thruster operating at $250-\mathrm{V}$ and $0.6-\mathrm{A}$ to 0.8 -A, over $10 \%$ of the high energy beam flux by number (over $20 \%$ by mass) at some angles was comprised of dimers. ${ }^{10}$
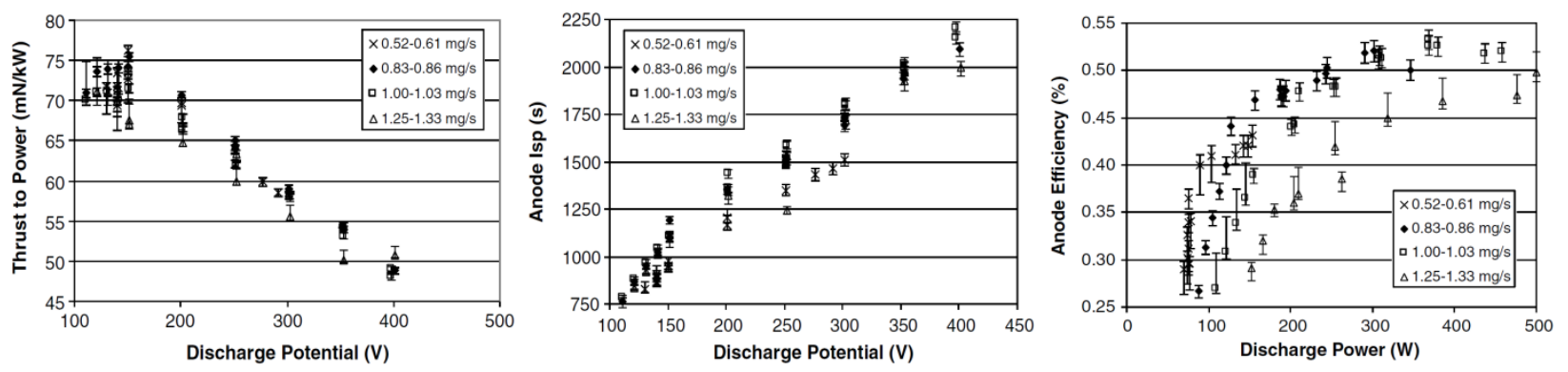

Figure 2. Thrust-to-power (left), anode $I_{S P}$ (center) and anode efficiency (right) from BHT-200 with iodine.

\section{2) BHT-1000 and BHT-8000}

Busek continued its iodine experiments with the BHT-1000 and BHT-8000. Performance trends with the BHT1000 were consistent with the earlier test data; iodine produced slightly lower specific impulse while demonstrating a higher thrust-to-power. Again, the efficiencies were comparable to xenon. The iodine performance of Busek's BHT- 8000 was measured between $2 \mathrm{~kW}$ and $10 \mathrm{~kW}$. High power testing showed slightly reduced anode efficiency with iodine, but the estimated uncertainty in these measurements was relatively high due to the iodine flow rate calibration.

Busek also tested hollow cathodes operated on iodine with both lanthanum hexaboride and C12A7 electride emitters. The latter may be preferred for very small spacecraft because it does not require a heater for the insert. 
Table 2. BHT-8000 Test Data for Iodine and Xenon

\begin{tabular}{|c|c|c|c|c|c|c|c|c|c|c|c|}
\hline & $\begin{array}{c}\text { Discharge } \\
\text { Voltage } \\
{[\mathrm{V}]}\end{array}$ & $\begin{array}{c}\text { Discharge } \\
\text { Current } \\
{[\mathrm{A}]}\end{array}$ & $\begin{array}{c}\text { Tank } \\
\text { Pressure* } \\
\text { [Torr] }\end{array}$ & $\begin{array}{c}\text { Discharge } \\
\text { Power } \\
{[\mathrm{W}]} \\
\end{array}$ & $\begin{array}{c}\text { Total } \\
\text { Power } \\
{[\mathrm{W}]} \\
\end{array}$ & $\begin{array}{l}\text { Thrust } \\
{[\mathrm{mN}]}\end{array}$ & $\begin{array}{c}\text { Discharge } \\
\text { Specific } \\
\text { Thrust } \\
\text { (mN/kW) } \\
\end{array}$ & $\begin{array}{c}\text { Anode } \\
\text { Isp } \\
{[\mathrm{s}]}\end{array}$ & $\begin{array}{c}\text { Total } \\
\text { Isp } \\
{[\mathrm{s}]} \\
\end{array}$ & $\begin{array}{c}\text { Anode } \\
\text { Efficiency } \\
{[\%]}\end{array}$ & $\begin{array}{c}\text { Thruster } \\
\text { Efficiency } \\
\text { [\%] }\end{array}$ \\
\hline Xenon & 200 & 9.8 & $4.2 \mathrm{E}-05$ & 1962 & 1972 & 146 & 74 & 1445 & 1313 & 53 & 48 \\
\hline Xenon & 201 & 10.1 & $2.7 \mathrm{E}-05$ & 2027 & 2034 & 151 & 74 & 1423 & 1293 & 52 & 47 \\
\hline lodine & 200 & 9.1 & $5.1 \mathrm{E}-05$ & 1816 & 2053 & 129 & 71 & 1302 & 1266 & 45 & 39 \\
\hline Xenon & 203 & 15.9 & $3.8 \mathrm{E}-05$ & 3224 & 3235 & 235 & 73 & 1524 & 1385 & 54 & 49 \\
\hline lodine & 199 & 15.6 & $5.5 \mathrm{E}-05$ & 3106 & 3118 & 223 & 72 & 1344 & 1321 & 50 & 49 \\
\hline Xenon & 302 & 10.0 & $3.2 \mathrm{E}-05$ & 3020 & 3036 & 199 & 66 & 1875 & 1705 & 60 & 55 \\
\hline lodine & 301 & 9.3 & $5.1 \mathrm{E}-05$ & 2787 & 2855 & 187 & 67 & 1796 & 1748 & 59 & 56 \\
\hline Xenon & 300 & 13.4 & $3.9 \mathrm{E}-05$ & 4029 & 4050 & 267 & 66 & 1927 & 1752 & 63 & 57 \\
\hline lodine & 301 & 12.3 & 4.7E-05 & 3702 & 3889 & 243 & 66 & 1803 & 1766 & 60 & 56 \\
\hline Xenon & 301 & 16.2 & 4.6E-05 & 4863 & 4893 & 321 & 66 & 1960 & 1782 & 63 & 57 \\
\hline lodine & 301 & 15.0 & 5.5E-05 & 4509 & 4547 & 297 & 66 & 1791 & 1760 & 61 & 56 \\
\hline Xenon & 401 & 9.9 & $4.8 \mathrm{E}-05$ & 3976 & 4018 & 226 & 57 & 2240 & 2036 & 63 & 56 \\
\hline lodine & 400 & 9.6 & $5.1 \mathrm{E}-05$ & 3856 & 4011 & 210 & 54 & 2122 & 2062 & 57 & 53 \\
\hline lodine & 400 & 12.7 & $4.70 \mathrm{E}-05$ & 5096 & 5240 & 295 & 58 & 2254 & 2206 & 64 & 61 \\
\hline lodine & 405 & 16.94 & 7.33E-05 & 6861 & 6951 & 407 & 59 & 2159 & 2075 & 63 & 60 \\
\hline lodine & 500 & 12.5 & 5.60E-05 & 6260 & 6360 & 334 & 53 & 2552 & 2498 & 67 & 64 \\
\hline lodine & 505 & 17.84 & 8.00E-05 & 9009 & 9100 & 474 & 53 & 2519 & 2420 & 65 & 62 \\
\hline
\end{tabular}

Plume measurements were also carried out with the BHT-1000. As seen earlier with the BHT-200, divergence of the ion beam current was less with iodine. For instance, at a discharge potential of $V_{d}=400-\mathrm{V}$ the $30^{\circ}$ half angle captured $90 \%$ of the iodine but only $86 \%$ of the xenon plume at a similar power level. For comparable impingement, the solar array and spacecraft plume keep-out half angle can be reduced by $5^{\circ}$. Testing also showed that the large angle beam could be effectively attenuated by the addition of a simple plume shield.

Based on measured BHT-1000 current densities and known vapor pressures, condensation upon spacecraft

surfaces was projected to be very minimal or non-existent. ${ }^{6}$ To avoid bulk accumulation of $I_{2}$ on surfaces, the removal rate must exceed the arrival rate. The flux away from a surface may be estimated from the $\mathrm{I}_{2}$ vapor pressure. At typical spacecraft surface temperatures, the vapor pressure of $I_{2}$ is two decades higher than that of $\mathrm{Hg}$ and four decades higher than that of Cs, both of which have been tested in space with ion engines. The vapor pressures are compared in Figure $4 .{ }^{11}$ The comparison with $\mathrm{Hg}$ is especially significant because $\mathrm{Hg}$ ion engines on the SERT II spacecraft were successfully fired on-orbit for 4000 hours. ${ }^{12}$ Most spacecraft surfaces, including solar arrays, were too warm to permit $\mathrm{Hg}$ condensation and showed no evidence of condensate. SERT II proved that condensable propellants are a viable option for electric satellite propulsion.

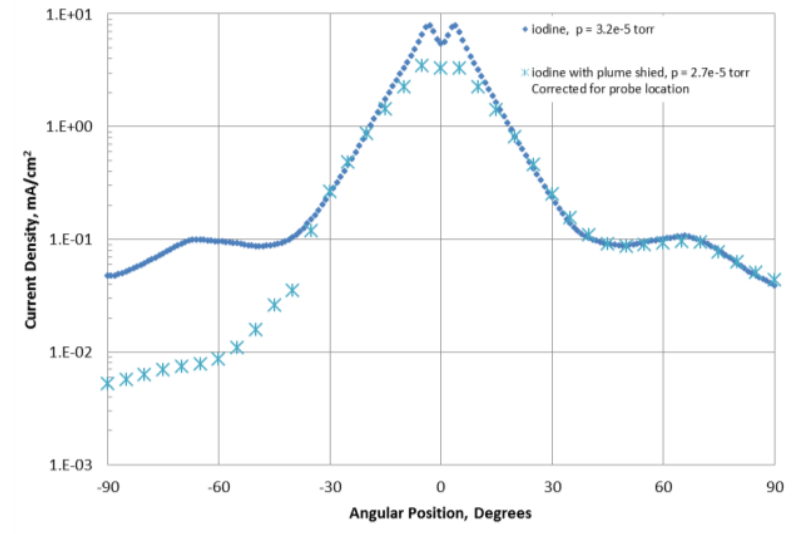

Figure 3. Plume Current Density (uncorrected for charge exchange) with and without Plume Shield, $500 \mathrm{~V}, 2 \mathrm{~A}$, Iodine.

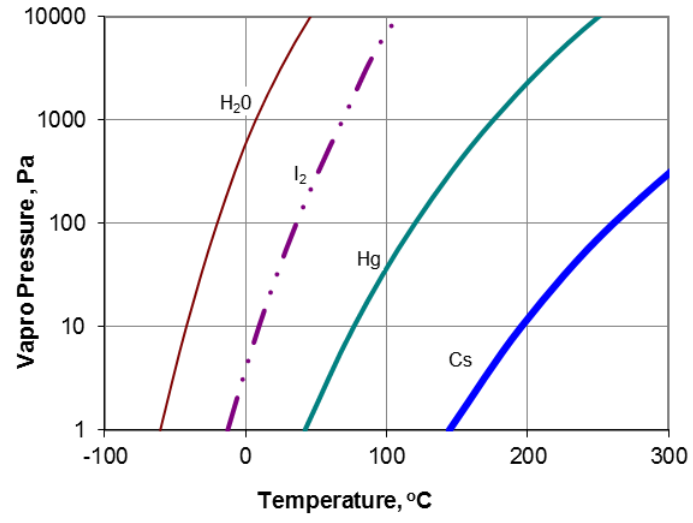

Figure 4. The vapor pressure of $I_{2}$ and other electric rocket propellants in Pascals.

\section{Development Plans}

Development remains prior to implementation of iodine Hall flight systems. NASA MSFC has developed a flight-like iodine feed system and is performing propellant transfer studies. NASA Glenn is leading iodine cathode investigations. Busek is currently working under a Small Business Innovative Research contract to deliver an engineering model (EM) 600W system. NASA MSFC has also purchased an EM model 200W thruster for testing to support a potential near-term demonstration mission.

Under the Space Technology Mission Directorate (STMD), the Game Changing Development (GCD) Program intends to fund the qualification of both the $200 \mathrm{~W}$ and $600 \mathrm{~W}$ systems starting in FY15. The GCD effort includes delivery of iodine cathodes, qualification model thrusters and PPUs at both $200 \mathrm{~W}$ and $600 \mathrm{~W}$, system level performance testing and environmental testing necessary. Hardware is planned for delivery in FY16. 


\section{Mission Applications}

A range of mission studies have been completed to identify mission level advantages using iodine as the primary propellant. In addition to iodine based missions for commercial, military, human and robotic exploration, multiple concepts have been developed for a low-cost high value technology demonstration mission. ${ }^{13}$ The mission benefits primarily result from two enabling features of iodine, the increased propellant density and low operating pressure.

\section{A. Microsatellites (Mass $<100 \mathrm{~kg}$ )}

The small satellite market continues to see strong growth in mission opportunities and subsystem capabilities. Small satellites offer rapid technology infusion opportunities and are validating the technologies required for interplanetary small satellite missions. The JPL Interplanetary NanoSpacecraft Pathfinder In a Relevant Environment (INSPIRE) was selected for a launch opportunity to become the first interplanetary CubeSat. INSPIRE has mission objectives to demonstrate and characterize nano-spacecraft communication, navigation, command and data handling, and mother-daughter relay communications. ${ }^{14}$ CubeSats are also being proposed for high value science; well beyond simple technology demonstrations.

One of the key limitations to small satellite exploration is still the lack of primary propulsion. The challenges are due to limited resources available: power, mass, and volume. Additionally, secondary spacecraft often have prohibitions for pressurized systems, hazardous propellants, stored energy, etc. Several cold and warm gas thrusters are mature and low-risk, but offer low specific impulse; limiting missions to $10 \mathrm{~s}$ of $\mathrm{m} / \mathrm{s} \Delta \mathrm{V}$. Milli-Newton hydrazine thrusters have been developed and tested, but require special handling and may drive up costs and limit secondary payload options. Small solid motors are also options, but likely require additional liquid propulsion; increasing system complexity and introduces its own constraints for handling and secondary payload accommodations. Electric propulsion systems appear to offer potential for either precision attitude control or high $\Delta \mathrm{V}$ capability. Pulsed plasma thrusters are the most mature, but vacuum arc thrusters and various alternatives are both low risk to mature and can offer modest attitude control. Miniature ion propulsion has been explored; offering high $\Delta \mathrm{V}$ potential, but requires high pressure gas. Microfluidic Electrospray Propulsion (MEP) technologies offer great potential, but still pose development risk and lifetime limitations. Given secondary payload requirements and constrained spacecraft resources, there are limited options available for both low-risk near-term infusion and high $\Delta \mathrm{V}$ primary propulsion for small spacecraft.

Even excluding concept maturity and operational constraints, small spacecraft are still volume constrained; especially as the spacecraft is pushed down to the smaller form factors (i.e. $6 \mathrm{U}$ and $12 \mathrm{U}$ spacecraft). The critical figure of merit moves towards propellant ISP-Density to determine the $\Delta \mathrm{V}$ capability of the spacecraft in a given volume. While figure 1 highlighted the storage density advantage of iodine over alternative electric propulsion options, figure 4 illustrates the ISP - Density of a range of propulsion options and resulting volume limited $\Delta \mathrm{V}$ capability assuming the propellant is limited to a $1 \mathrm{U}$ volume allocation of a $6 \mathrm{U}$ spacecraft. Results in figure 5 do not account for propulsion system mass fraction or supporting subsystem requirements. Figure 5 indicates the potential merit of iodine based propulsion due to the combined benefits of high specific impulse and high storage density.

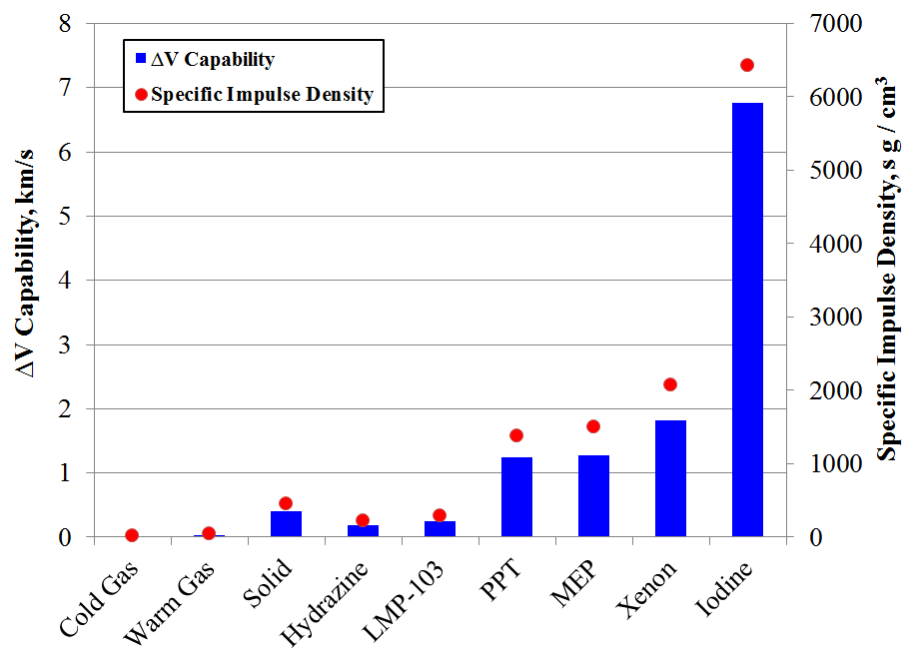

Figure 5. $I_{\mathrm{SP}}$-Density and $1 \mathrm{U} \Delta \mathrm{V}$ capability for a $6 \mathrm{U}$ Spacecraft.

1) Geocentric Missions

As discussed previously, the SmallSat market is showing tremendous growth potential, however; SmallSats still have limited capabilties beyond the propulsion limitations. The Department of Defense (DoD), NASA and industry have shown significant interest in LEO SmallSat applications. SpaceWorks Enterprises, Inc. projects between 2,000 and 2,750 nano and microsatellite launches between 2014 and 2020; ranging from 1-50kg in mass. ${ }^{15}$ Both military and civil space plans include deployment of large constellations of SmallSats in LEO for communciation and imaging capabilities. ${ }^{16}$ Figure 5 provides notional constellations for communcation and imagery. The community 
continues to investigate responsive capabilities for SmallSats, either through a responsive launch capability or a responsive space deployed maneuverability capability. The capability for high $\Delta \mathrm{V}$ maneuvers on SmallSats may enable low cost constellation deployment, orbit tranfer to higher value orbits and provide station keeping for either formation flying or drag makeup. These capabilities enable geocentric applications including low-cost access to high value orbits, presistant coverage constellations, and required de-orbit capability.

Both $6 \mathrm{U}$ and $12 \mathrm{U}$ iodine spacecraft have been studied in great detail for LEO applications. ${ }^{13}$ A preliminary Mass Equipment List (MEL) for a 12U iodine satellite example with a $2 \mathrm{~kg}$ payload can carry more than $5 \mathrm{~kg}$ of iodine and fit within the $20 \mathrm{~kg}$ standard mass requirement. At $250 \mathrm{~V}$ discharge voltage, the $12 \mathrm{U}$ iSAT is capable of approximately $4 \mathrm{~km} / \mathrm{s}$ of $\Delta \mathrm{V}$ and also well within the predicted life capability of the BHT-200 on iodine. The $\Delta \mathrm{V}$

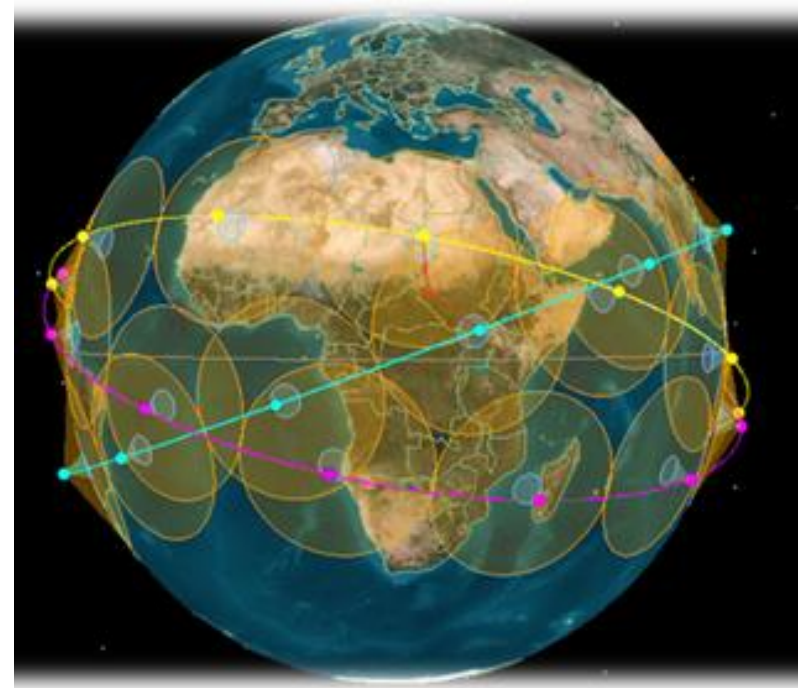

Figure 6. Example constellations achievable from a single starting orbit with iodine propelled SmallSats. capability can be used for more than $20,000 \mathrm{~km}$ of altitude change or inclination change of 30 degrees in LEO or 80 degrees at GEO. A combination of propulsive manuevers and nodal regression and can easily accommodate a node

Table 3. Preliminary MEL for 12U iSAT in LEO

\begin{tabular}{|c|c|c|c|c|}
\hline iSAT Mass Estimation List - 12U LEO & Basic Mass (kg) & MGA (\%) & MGA (kg) & Predicted Mass (kg) \\
\hline \begin{tabular}{l|l|}
1.0 & Structures \\
\end{tabular} & 1.601 & $30 \%$ & 0.480 & 2.081 \\
\hline \begin{tabular}{|l|l|}
2.0 & Mechanisms \\
\end{tabular} & 0.100 & $30 \%$ & 0.030 & 0.130 \\
\hline \begin{tabular}{l|l|}
3.0 & Thermal \\
\end{tabular} & 0.334 & $30 \%$ & 0.100 & 0.434 \\
\hline \begin{tabular}{l|l}
4.0 & Power \\
\end{tabular} & 2.052 & $30 \%$ & 0.616 & 2.668 \\
\hline \begin{tabular}{|l|l|}
5.0 & Guidance Navigation \& Control \\
\end{tabular} & 1.518 & $10 \%$ & 0.152 & 1.670 \\
\hline 6.0 Communications & 0.090 & $6.00 \%$ & 0.005 & 0.095 \\
\hline \begin{tabular}{l|l}
7.0 & Command and Data Handling \\
\end{tabular} & 0.324 & $16 \%$ & 0.053 & 0.377 \\
\hline \begin{tabular}{l|l}
8.0 & Propulsion \\
\end{tabular} & 3.846 & $25 \%$ & 0.965 & 4.811 \\
\hline Dry Mass & 9.864 & $24 \%$ & 2.401 & 12.265 \\
\hline \begin{tabular}{l|l|}
9.0 & Payload \\
\end{tabular} & 2.000 & $30 \%$ & 0.600 & 2.600 \\
\hline \begin{tabular}{|l|l|}
10.0 & Non-Propellant Fluids \\
\end{tabular} & 0.000 & $0 \%$ & 0.000 & 0.000 \\
\hline Inert Mass & 11.864 & $25 \%$ & 3.001 & 14.865 \\
\hline \begin{tabular}{|l|l|} 
11.0 & Propellant (Solid Iodine) \\
\end{tabular} & 5.135 & & 0.000 & 5.135 \\
\hline iSAT 12U LEO Total Mass & 16.999 & & 3.001 & 20.000 \\
\hline
\end{tabular}

2) Interplanetary Missions

NASA has outlined planetary science and human exploration objectives to a diverse set of interplanetary targets. The community continues to stress the desire to increase the cadence of mission opportunties to accelerate exploration from asteroids, comets, Mars, Mars' Moons, outer planets, etc. It is infeasible for NASA to meet it's objectices with mission costs $>>100 \mathrm{M}$ each in addition to the high launch costs also $>>100 \mathrm{M}$. NASA has recently announced the opportunity to leverage the first SLS Engineering Model flight (EM-1) with secondary payload opportunities. These opportunities are for $6 \mathrm{U}$ and potentially $12 \mathrm{U}$ volume spacecraft launched into an escape trajectory. However, the mission value is greatly increased with post-launch $\Delta \mathrm{V}$. The NEA Scout mission was selected under the Advanced Exploration Systems (AES) Program to develop a 6U solar sail spacecraft to enable an asteroid reconnassance flyby mission. Like solar sails, iodine Hall systems have a niche to provide high $\Delta \mathrm{V}$ in volume constrained spacecraft for asteroid flyby and orbiter mission.

NASA MSFC has assessed the 12U interplnaetary iodine Satellite (iiSAT) for near-Earth asteroid exploration at very low cost. If deployed on an escape trajectory, the iiSAT vehcile has sufficient propulsion capability to redezvous with a wide range of near-Earth targets. The baseline mission is a rendezvous with 2000 SG344, a target of interest as a potential crew rendezvous destination or an Asteriod Redirect Mission target. The iiSAT vehcile with approximtely $2.5 \mathrm{~km} / \mathrm{s}$ of $\Delta \mathrm{V}$ capability is shown in figure 7 .

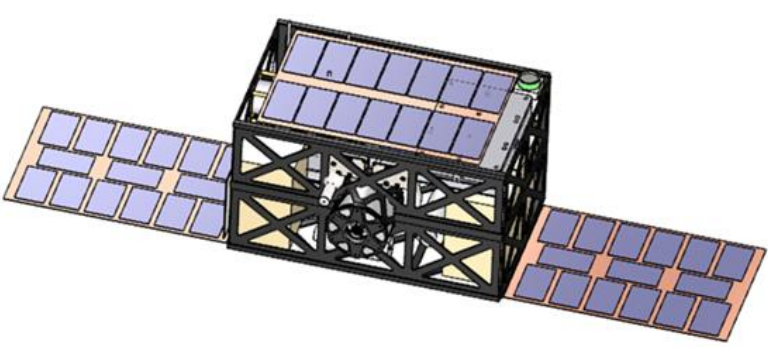

Figure 7. 12U iiSAT preliminary concept design. 


\section{B. SmallSats (Mass $<300 \mathrm{~kg}$ )}

Multiple studies have been performed with the NASA GRC COMPASS team and the NASA MSFC Advanced Concepts Office to assess the viability of SmallSats to delivery high value science for low-cost. The goal of the studies included the ability to delivery representative Discovery mission class science payloads to targets of interest. The studies include mission concept development, preliminary spacecraft design and life cycle cost assessment.

\section{1) Near-Earth Asteroid Orbiter}

The COMPASS team from NASA GRC evaluated a mission to a near-Earth asteroid using a secondary launch into geosynchronous transfer orbit (GTO). The GTO launch would result in $>\$ 100 \mathrm{M}$ in launch cost savings over a dedicated interplanetary launch. Using an EELV Secondary Payload Adapter (ESPA) Grande, secondary launch providers can deploy up to $300 \mathrm{~kg}$ to GTO for an advertised cost of just under $\$ 10 \mathrm{M} .{ }^{17}$ The ESPA Grande with the stowed NEA orbiter is shown in figure 8 .

The study proposed a solution using two BHT-600 iodine

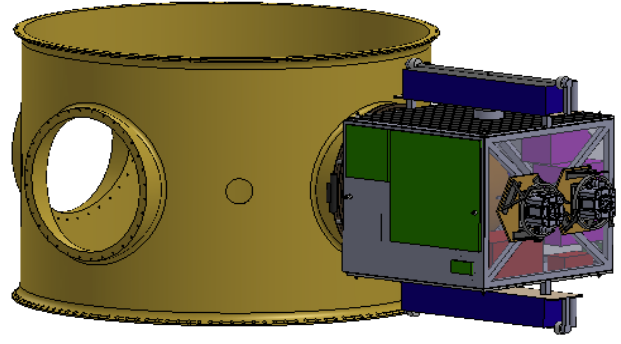

Figure 8. ESPA Grande with stowed vehicle. thrusters and a spacecraft power of $1500 \mathrm{~W}$ at End-of-Life. The mission requires a slow spiral of approximately seven months to escape. After escape, the spacecraft provides additional $\Delta \mathrm{V}$ for the interplanetary transfer to the target of interest. The baseline target was 1999 RQ36, but a large range of viable asteroid targets exist the same spacecraft. The system carries $13 \mathrm{~kg}$ of science and provides a total mission $\Delta \mathrm{V}$ of $9.6 \mathrm{~km} / \mathrm{s}$. The science payload was defined by a principal investigator from The Johns Hopkins University Applied Physics Laboratory representative of Discovery class science return including visible and IR imaging, and terrain and gravity field mapping capabilities. The driving constraint for the spacecraft design was the volume limitation.

Table 4. Preliminary MEL for NEO Orbiter.

\begin{tabular}{|c|c|c|}
\hline Main Subsystems & $\begin{array}{l}\text { Predicted } \\
\text { Mass (kg) }\end{array}$ & $\begin{array}{c}\text { Aggregate } \\
\text { Growth (\%) }\end{array}$ \\
\hline i2Hall Spacecraft & 272 & \\
\hline SEP Bus & 272 & $7 \%$ \\
\hline \multirow{3}{*}{$\begin{array}{l}\text { Science Payload } \\
\text { Attitude Determination and Control } \\
\text { Command \& Data Handling }\end{array}$} & 13 & $0 \%$ \\
\hline & 5 & $3 \%$ \\
\hline & 8 & $28 \%$ \\
\hline \multirow{3}{*}{$\begin{array}{l}\text { Communications and Tracking } \\
\text { Electrical Power Subsystem } \\
\text { Thermal Control (Non-Propellant) }\end{array}$} & 7 & $10 \%$ \\
\hline & 29 & $25 \%$ \\
\hline & 22 & $15 \%$ \\
\hline \multirow{2}{*}{$\begin{array}{l}\text { Propulsion (Chemical Hardware) } \\
\text { Propellant (Chemical) }\end{array}$} & 5 & $0 \%$ \\
\hline & 1 & $0 \%$ \\
\hline \multirow{2}{*}{$\begin{array}{l}\text { Propulsion (EP Hardware) } \\
\text { Propellant (EP) }\end{array}$} & 25 & $10 \%$ \\
\hline & 131 & Togrll \\
\hline \multirow{2}{*}{$\begin{array}{l}\text { Structures and Mechanisms } \\
\text { Element } 1 \text { consumables (if used) }\end{array}$} & 27 & $17 \%$ \\
\hline & 0 & \multirow{3}{*}{$14 \%$} \\
\hline Estimated Spacecraft Dry Mass (no prop,consum) & 139 & \\
\hline Estimated Spacecraft Wet Mass & 272 & \\
\hline \multicolumn{2}{|l|}{ - Growth Calculations SEP Bus } & Total Growth \\
\hline Dry Mass Desired System Level Growth & 142 & $30 \%$ \\
\hline Additional Growth (carried at system level) & & $14 \%$ \\
\hline Total Wet Mass with Growth & 287 & \\
\hline
\end{tabular}

The desire for efficient power packaging and physical envelope constraints led to a design leveraging two 800W Roll-Out Solar Arrays (ROSA). The preliminary concept design of the near-Earth asteroid explorer is shown in figure 9 in the deployed configuration and the MEL is provided in table 4.The full life cycle cost of the mission, including launch costs, 3 years of mission operations and 5 months of science operations, but not including the science instrument costs is estimated to be $\$ 130 \mathrm{M}$. The authors note that the equivalent xenon system was insufficient to meet the mission needs due to the propellant tank volume requirement.
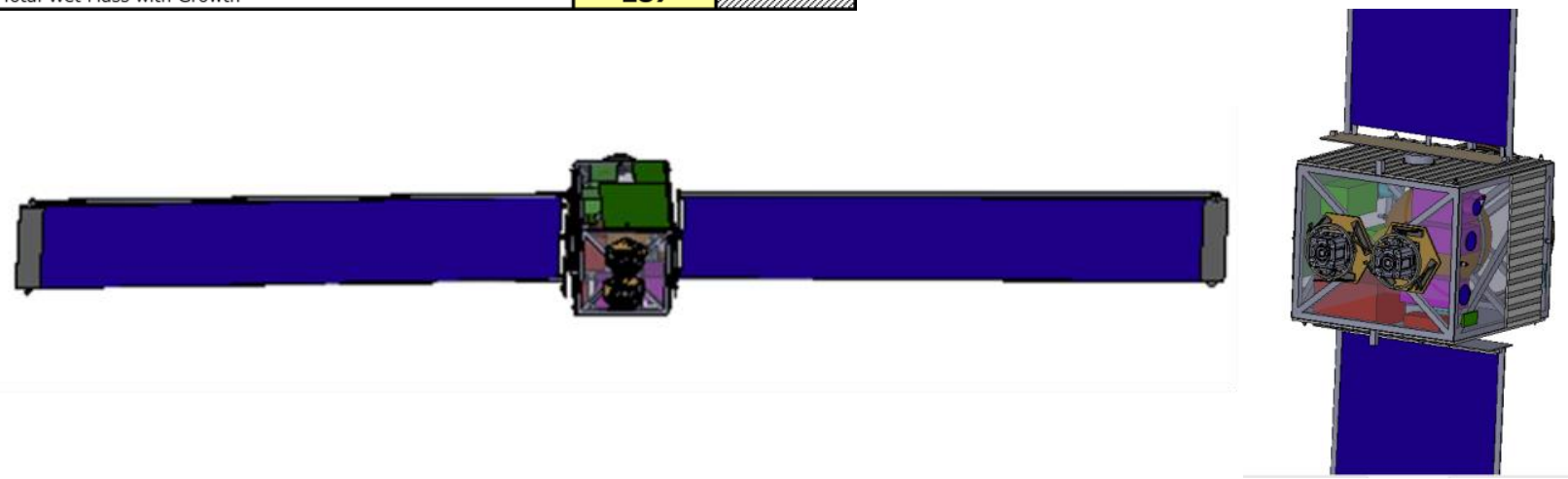

Figure 9. Near-Earth-asteroid orbiter concept design in deployed configuration. 


\section{2) Low-Cost Discovery Lunar Orbiter}

Another similar study was performed by the MSFC Advanced Concepts Office with mission design support from the Glenn Research Center to assess the potential to achieve Discovery class science at the moon at a cost cap well below the current limitation. Again, in order to achieve drastic cost savings, the launch was constrained to a GTO deployment as a secondary spacecraft and then leverages the iodine electric propulsion system for the spiral phases from GTO to Low-Lunar Orbit (LLO). The trajectory is very similar to that previously demonstrated by the European Space Agency's (ESA) first Small Missions for Advanced Research in Technology (SMART-1) spacecraft. Unlike SMART-1, the iodine system can launch as a secondary payload and fit within the physical constraints available to the ESPA Grande. SMART-1 was with a mass $367 \mathrm{~kg}$ wet mass including $84 \mathrm{~kg}$ of xenon, approximately $20 \%$ more than allowable by the ESPA Grande.

The science objectives of the Low-Cost Discovery Lunar Orbiter required the spacecraft to perform very low altitude polar flybys. The spacecraft initially spirals down to a $100 \mathrm{~km}$ circular orbit. After completing an initial science phase of 90 days, the spacecraft is then lowered into a $100 \mathrm{~km} \times 15 \mathrm{~km}$ orbit with the perilune over the pole. The $15 \mathrm{~km}$ perilune is maintained for 60 days before transitioning to a higher risk and reduced perilune orbit. The electric propulsion system has sufficient control authority to maintain a perilune error on the order of $1 \mathrm{~km}$ with apolune station keeping. Note the perilune error approaches $2.5 \mathrm{~km}$, but that error occurs while the spacecraft is at apolune. Figure 10

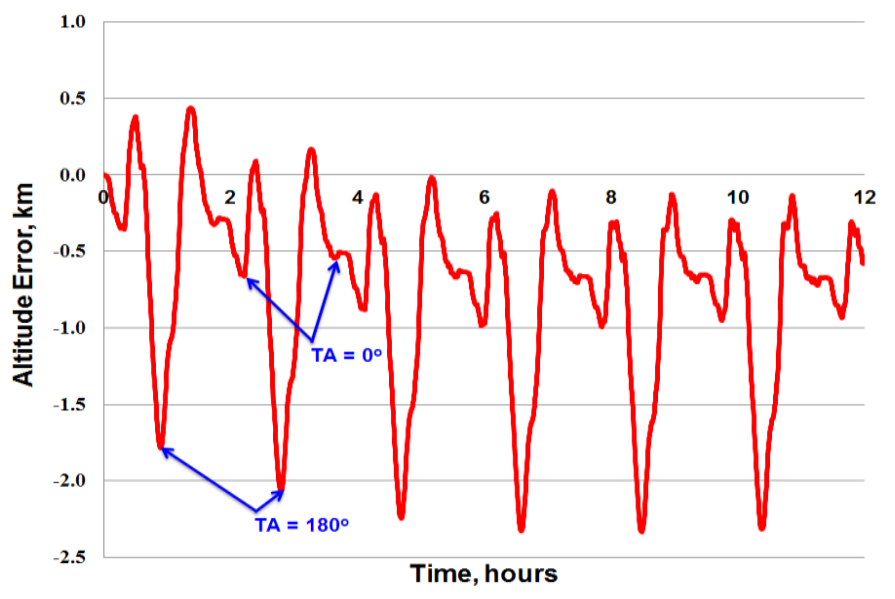

Figure $10.100 \mathrm{~km} \times 15 \mathrm{~km}$ perilune errors. illustrates the perilune error potential over the orbit for a 12 hour period during the $100 \mathrm{~km} \mathrm{x} 15 \mathrm{~km}$ science phase. The orbit is relatively unstable at the low altitudes, and there are regions with high mountains relative to the flyby altitude. Finally, the propulsion system can lower the spacecraft to a $100 \mathrm{~km} \times 5 \mathrm{~km}$ orbit with approximately 20 minute station keeping maneuvers required every 12 hours. A 50x50 lunar gravity model was used to support the low flyby trajectory analyses. This is a high risk phase of the mission, where the spacecraft would impact the lunar surface without station-keeping for 24-30 hours. Additionally, over a few regions of the moon, the perilune must be raised to avoid surface contact.

The low-cost lunar orbiter has similar attrbutes to the near-earth asteroid orbiter. In fact, there is potential for a common bus to provide with similar power and propulsion systems. The spacecraft is based on using two BHT-600 iodine thrusters for primary propulsion. The power system is sized to provide $1.7 \mathrm{~kW}$ at beginning of life, sufficient to maintain full power to the thrusters at end-of-life including radiation degredation, $10 \%$ margin on the thrusters and $30 \%$ power margin for the remainng subsystems. The avionics are strategicaly placed in the spacecraft to increase the effective radiation shielding. The spacecraft uses the heritage Lunar Atmosphere and Dust Envirnonment Explorere (LADEE) communication system in S-band. Similar to the asterid orbiter, the total life

Table 5. Preliminary MEL for the Lunar Orbiter.

\begin{tabular}{|c|c|c|c|c|}
\hline \multicolumn{2}{|c|}{ Mass Estimation List (MEL) } & $\begin{array}{c}\text { Basic } \\
\text { Mass } \\
(\mathrm{kg})\end{array}$ & $\begin{array}{c}\text { ave MGA } \\
(\%)\end{array}$ & $\begin{array}{c}\text { Predicte } \\
\text { d Mass } \\
\text { (kg) }\end{array}$ \\
\hline 1.0 & Structures & 21.2 & $30 \%$ & $2756 \%$ \\
\hline 2.0 & \multicolumn{3}{|l|}{ Mechanisms - In Subsystems } & 0.0 \\
\hline 3.0 & Thermal & 4.8 & 0.3 & 6.0 \\
\hline 4.0 & Power & 90.6 & 0.2 & 107.2 \\
\hline 5.0 & Guidance Navigation \& Control (GN\&C) & 8.4 & 0.1 & 9.8 \\
\hline 6.0 & Communications & 6.8 & 0.3 & 8.5 \\
\hline 7.0 & Command and Data Handling (C\&DH) & 7.9 & 0.3 & 10.1 \\
\hline 8.0 & Propulsion & 17.3 & 0.1 & 17.3 \\
\hline \multicolumn{2}{|c|}{ Dry Mass } & 157.0 & $16 \%$ & 186.6 \\
\hline 9.0 & Insturments & 10.1 & 0.2 & 12.2 \\
\hline 10.0 & Non-Propellant Fluids & 0.0 & $0 \%$ & 0.0 \\
\hline \multicolumn{2}{|c|}{ Inert Mass } & 167.2 & $16 \%$ & 198.7 \\
\hline \multicolumn{5}{|c|}{\begin{tabular}{|l|l|}
11.0 & Propellant \\
\end{tabular}} \\
\hline & 11.1 Nitrogen (Cold Gas) & 9.4 & $5 \%$ & 9.9 \\
\hline & \begin{tabular}{|l|l|}
11.2 & lodine \\
\end{tabular} & 87.0 & $3 \%$ & 89.6 \\
\hline \multicolumn{2}{|c|}{ Total Mass } & 263.6 & & 298.2 \\
\hline
\end{tabular}
cycle cost of the mission, including launch costs, operations and the instrument package is estimated at \$149M. The spacecraft MEL and configuration are provided in table 5 and figure 11 respectively.

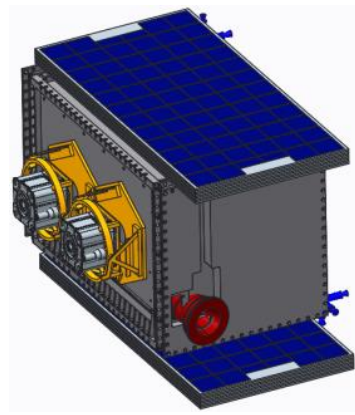

Figure 11. 12U iiSAT preliminary concept design. 


\section{3) SmallSat Interplanetary Potential}

More than 20 years ago, NASA selected 11 concept studies that evolved into the Discovery mission program. The Discovery program was focused on "costs limited to no more than $\$ 150 \mathrm{M}$ and acceptance of greater level of risk". The decadal survey emphasizes the Discovery program value and stresses the need to continue frequent opportunities to make progress on key science objectives. The more recent announcement of opportunities request missions capped $\sim \$ 0.5 \mathrm{~B}$, and the selection reviews are shown to have limited tolerance to risk. Small spacecraft continue to increase mission potential through evolutionary and revolutionary technology advancements for subsystems with reduced demands on limited spacecraft resources. The application benefits of the iodine Hall system can enable interplanetary missions for asteroid reconnaissance, missions to the moon, Venus, Mars as secondary payloads on frequent launch opportunities. Additionally, iodine Hall systems can enable high value science on daughter spacecraft or provide strategic deployment of multiple propulsion limited systems. The use of an iodine propulsion with small spacecraft "can deliver high-return missions that are cost-effective, quicker from concept to launch, and responsive to the present budget climate. They promise to revolutionize the way we carry out planetary science in the next century." 18

\section{Orbit Transfer Vehicles}

Electric propulsion systems are routinely considered for orbit transfer vehicles (OTV). Long range exploration or even commercial space architectures leverage the use of electric propulsion stages and OTVs. Spaceflight Services is now offering a SHERPA hosted payload system with integrated in-space propulsion starting in both LEO and GTO. The SHERPA can be used to deploy SmallSats in higher value orbits. The post launch $\Delta \mathrm{V}$ capability is of course limited by the performance of the on-board propulsion system, notably the specific impulse and packaging efficiency. The near-term focus has been on ESPA based options. ESPA based OTVs using xenon based systems are capable of delivering payloads from GTO to GEO and even out to Mars. A single system sent to Mars could deliver SmallSats or a large number of CubeSats to the moons of Mars or into a constellation for communication or observations at Mars. ${ }^{19}$ Figure 11 illustrates an ESPA based orbit transfer vehicle using xenon propellant. Based on the density improvement with iodine, sufficient propellant can be placed entirely within the ESPA ring for transits to Mars, allowing for two additional slots for secondary payloads. The change of propellant choice, recall the power processing units are identical and performance is comparable, would result in minimum revenue increase potential of $\$ 10 \mathrm{M}$, and that would be for the LEO slots. Higher potential revenue gains are expected for payloads beyond LEO. ${ }^{20}$ Concept designs of an ESPA OTV for standard payloads $(180 \mathrm{~kg})$ or CubeSat P-POD arrays is shown in figure 12.
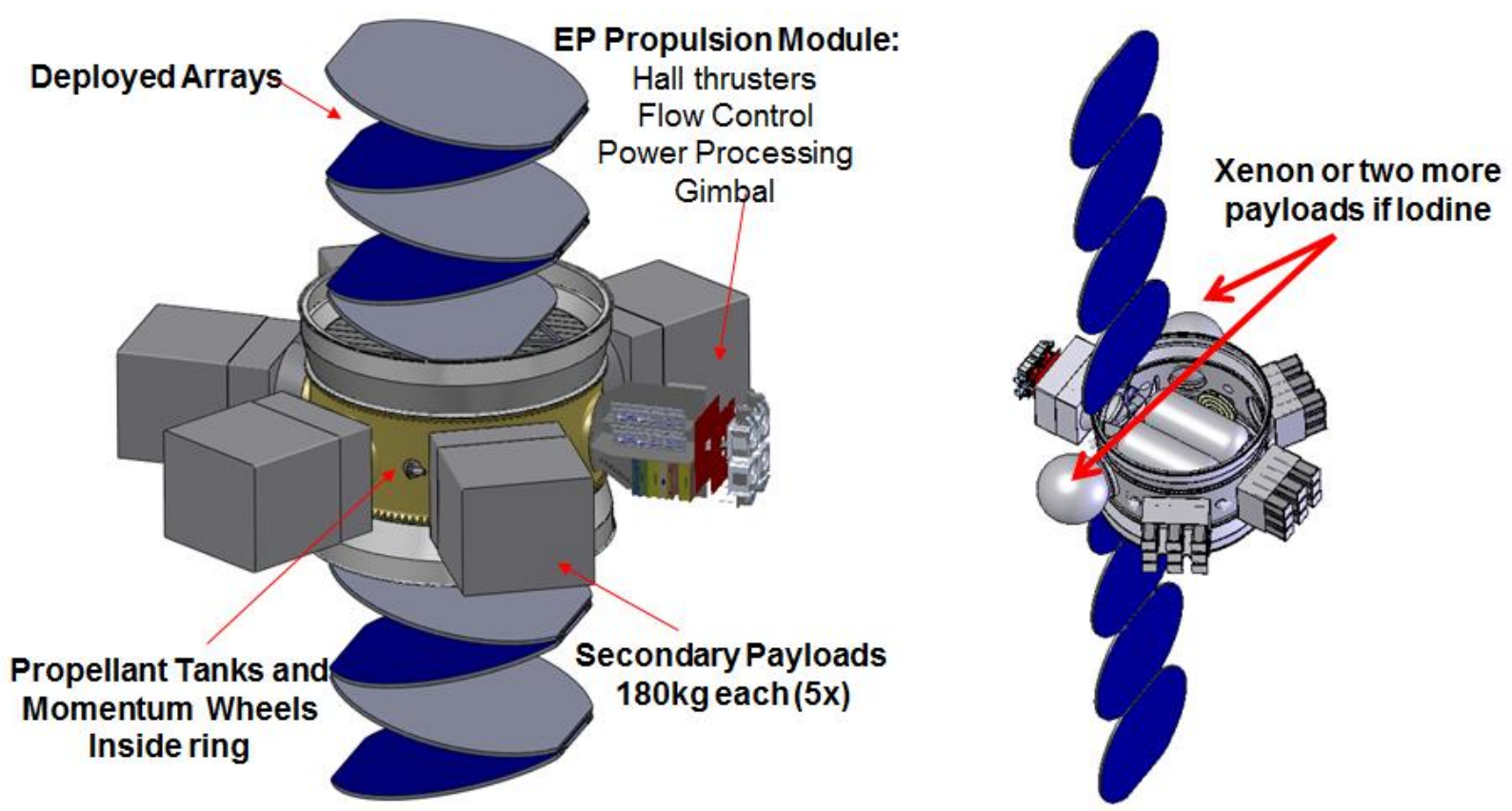

Figure 12. ESPA Based OTV concepts. 


\section{Exploration Class}

Exploration class systems are not as constrained with respect to volume as SmallSats. Although some shroud options and propellant configurations can present packaging challenges; especially with very large $>100 \mathrm{~kW}$ solar arrays. The propellant tanks are expected to be significantly lower cost and lower risk to develop for the very low operating pressures. The propellant can be placed in more packaging efficient cylinders over domed pressure vessels beyond existing manufacturing practices. The GRC COMPASS team performed a large number of propulsion trades for comparison to the Mars Design Reference Architecture 5.0. ${ }^{20}$ The results indicated a potential advantage for pairing a solar electric propulsion (SEP) chemical propulsion stage for a bimodal (high thrust / low thrust) option (SEP-Chem) without the need to develop a nuclear thermal rocket propulsion system. ${ }^{21}$ The initial studies were based on an $800 \mathrm{~kW}$ xenon SEP system. The COMPASS team completed a comparison if iodine was used in place of the xenon and several findings were made. First, the increase in storage density was never a driving constraint for the specific mission. The large SEP stage was driven by solar array packaging, but both the xenon and iodine options fit well within the smallest of shroud options. Second, the propellant cost and propellant tank development for iodine was estimated as a $\sim \$ 400 \mathrm{M}$ total cost savings. Finally, the reduced mass of the iodine tank and support structure lead to $3,000 \mathrm{~kg}$ mass savings, and with system gear-ratio; the total initial mass to LEO was reduced by more than $8 \mathrm{t}$. Based on the system configurations, the savings also resulted in one less launch; assumed to be an automated transfer vehicle for additional cost savings $\sim \$ 300 \mathrm{M}$. After a detailed design of the crew vehicle and final performance of the Space Launch System is known, it is not clear if an $8 \mathrm{t}$ system would become a significant driver. The iodine system was the only propulsion option that fit entirely within two SLS launches; a habitat module and a SEP module. The mass savings between the xenon and iodine systems are provided in

Table 6. Mass savings using iodine.

\begin{tabular}{|l|c|}
\hline \multicolumn{1}{|c|}{ Mass summaries (kg) } & $\begin{array}{c}\text { Savings, kg } \\
\text { (Xe vs Iodine) }\end{array}$ \\
\hline SEP Piloted SLS Launch 1 - HAB Module Totals \\
\hline HAB Module Wet Mass & 4983 \\
\hline HAB Module Dry Mass & 1378 \\
\hline HAB Module Inert Mass & 1743 \\
\hline HAB Module Total Chem Prop & 199 \\
\hline HAB Module Xe Prop & 3406 \\
\hline SEP Piloted SLS Launch 2 - SEP Module Totals \\
\hline SSEP Module Wet Mass & $\mathbf{3 4 3 1}$ \\
\hline SEP Module Dry Mass & 1487 \\
\hline SEP Module Inert Mass & 1795 \\
\hline SEP Module Total Chem Prop & 1112 \\
\hline SEP Module Total Xe Prop & $\mathbf{8 3 2}$ \\
\hline Vehicle totals & \\
\hline Total Vehicle Wet Mass & 8414 \\
\hline Total Vehicle Dry Mass & $\mathbf{2 8 6 5}$ \\
\hline Total Vehicle Inert Mass & $\mathbf{3 5 3 9}$ \\
\hline Total Chem Prop & $\mathbf{1 3 1 1}$ \\
\hline Total Xe Prop & $\mathbf{4 2 3 8}$ \\
\hline
\end{tabular}
table 6, and the SEP crew vehicle concept design is shown in figure 13.

Two secondary observations are noted for the applicability of iodine for exploration class systems. First, one of the primary concerns with large throughput and operating time missions for iodine is the cathode. However, for these large scale systems, the small cathode propellant requirement could be a secondary xenon system for just cathode operation and would have minimal total system configuration impact. Second, and potentially a more significant advantage of iodine, is the impact on ground performance testing. Current test capabilities within NASA are already pushing the limits of what may be required for thruster testing and qualification, even for a $10 \mathrm{~kW}$ class thruster. Operating at higher specific impulse helps significantly, but there are few viable options for ground testing $100 \mathrm{~kW}$ class xenon thrusters and fully characterizing facility impacts on the system performance. The use of iodine propellant allows for a relatively low-cost option to use cold surfaces for iodine condensation and minimize facility effects. As NASA continues to pursue very high power electric propulsion options, sufficient performance and lifetime ground test conditions should be established for the determination of sufficient ground test capabilities.

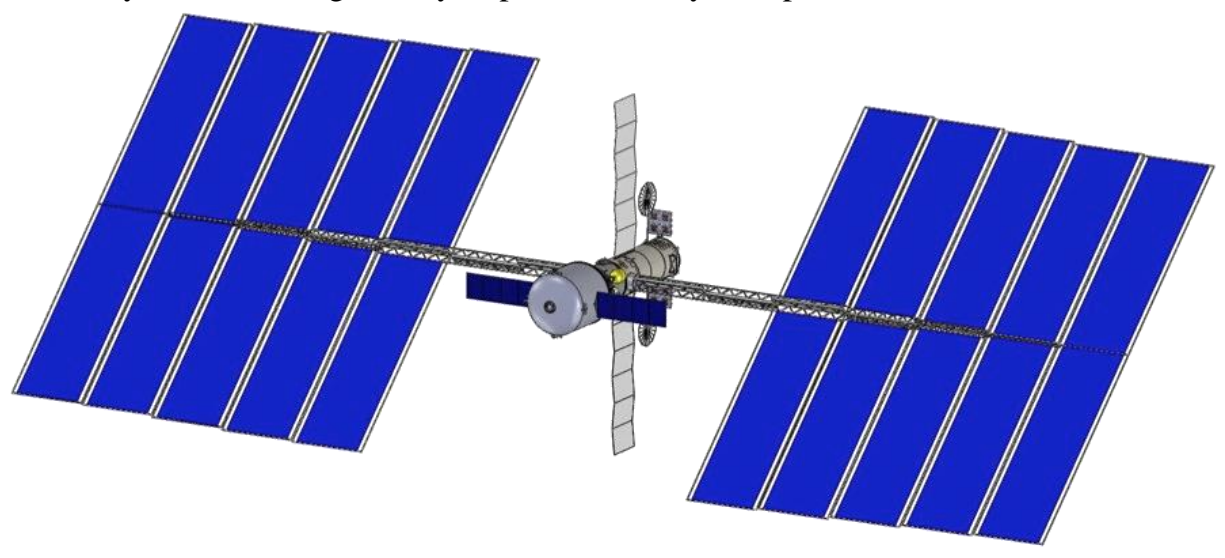

Figure 13. SEP crew nodule for Mars SEP/Chem option. 


\section{Summary}

Iodine has similar performance as the SOA xenon Hall systems, can leverage xenon PPU investments and has potential system level benefits primarily due to increased storage density and very lower operating pressures. Iodine Propulsion remains one of the key limitations for small satellite missions and iodine may be enabling due to the potential $\Delta \mathrm{V}$ per unit volume. Additional advantages for secondary payloads include long term quiescence potential, no pre-launch pressurization required, and no special handing requirements. Iodine may enable a new set of planetary and exploration class missions by packaging sufficient $\Delta \mathrm{V}$ within secondary payload constraints to enable GTO launched secondary spacecraft to transit to the moon, asteroids, and other interplanetary destinations for $\sim \$ 150 \mathrm{M}$ full life cycle cost including the launch. ESPA based OTVs are also volume constrained and a shift from xenon to iodine can significantly increase the transfer vehicle $\Delta \mathrm{V}$ capability or enable additional secondary payloads for increases revenue potential. Exploration class electric propulsion systems may also benefit from iodine over xenon due to decreased propellants costs, propellant tank mass costs and system level mass impacts. Finally, iodine may also have a secondary benefit to the ground system performance and qualification approach for high flow rate system.

\section{Acknowledgments}

Resources were provided for this work in part by the Advanced In-Space Propulsion project under the Space Technology Mission Directorate and NASA's science mission directorate under directed research and technology. The authors wish to thank the entire COMPASS and ACO teams and Laura Burke for the additional trajectory design support.

\section{References}

${ }^{1}$ Massey, D., King, L, Makela, J., "Development of a Direct Evaporation Bismuth Hall Thruster," 44th AIAA/ASME/SAE/ASEE Joint Propulsion Conferencet, AIAA Paper 2008-4520, Hartford, CT, 2008.

${ }^{2}$ Sengupta, A., Marrese-Reacing, C., Semenkin, A., Zakharenkov, L., Tverdokhlebov, S., Tverdokhlebov, O. et al., "Summary of the VHITAL Thruster Technology Demonstration Program: A Two-Stage Bismuth-Fed Very High Specific Impulse TAL", Proceedings of the 30th International Electric Propulsion Conference, IEPC Paper 2007-005, Florence, Italy, 2007

${ }^{3}$ Grishin, S. D. and Leskov, L. V., Electrical Rocket Engines of Space Vehicles, Mashinostroyeniye, Moscow, 1989.

${ }^{4}$ Hruby, V.,Monheiser, J., Pote, B., Freeman, C., and Connolly,W., "Low Power, Hall Thruster Propulsion System,” IEPC 1999092, Proceedings of the $26^{\text {th }}$ International Electric Propulsion Conference, Kitakyushu, Japan, Oct 1999.

${ }^{5}$ Szabo, J., Pote, B., Paintal, S., Robin, M., Hillier, A., Branam, R. D., and Huffman, R. E., "Performance Evaluation of an Iodine-Vapor Hall Thruster," Journal of Propulsion and Power, Vol. 28, No. 4, July - August 2012

${ }^{6}$ Szabo, J., Robin, M., Paintal, S., Pote, B., and Hruby, V., "High Density Hall Thruster Propellant Investigations," $48^{\text {th }}$ Joint Propulsion Conference, AIAA 2012-3852, Atlanta, GA, July 30 - August 1, 2012.

${ }^{7}$ Szabo, J., Robin, M., Paintal, S., Pote, B., Hruby, V., and Freeman, C., "Iodine Propellant Space Propulsion," IEPC 2013-311, $33^{\text {rd }}$ International Electric Propulsion Conference, Washington D.C., October 6-10, 2013.

${ }^{8}$ Haag, T., Rev. Sci. Instrum. 62, 1186, 1991.

${ }^{9}$ Hillier, A., "Revolutionizing Space Propulsion Through the Characterization of Iodine as Fuel for Hall-Effect Thrusters," M.S. Thesis, Air Force Institute of Technology, Wright-Patterson Air Force Base, Ohio, 2011.

${ }^{10}$ Szabo, J., Robin, M., "Iodine Plasma Species Measurements in a Hall Effect Thruster Plume," Accepted for publication in AIAA Journal of Propulsion and Power, 9 April 2014.

${ }^{11}$ CRC Handbook of Chemistry and Physics, 83rd Edition, CRC Press LLC, 2002.

${ }^{12}$ Kerslake, W., and Ignaczak, L., "Development and Flight History of SERT II Spacecraft," $28^{\text {th }}$ AIAA/SAE/ASME/ASEE Joint Propulsion Conference and Exhibit, AIAA-92-3516, July 1992.

${ }^{13}$ Dankanich, J. W., Polzin, K. A., Calvert, D., and Kamhawi, H., "The iodine Satellite (iSAT) Hall Thruster Demonstration Mission Concept and Development," 50 ${ }^{\text {th }}$ Joint Propulsion Conference, Cleveland, OH, July 28-30, 2014.

${ }^{14}$ Klech, A., et al., "INSPIRE: Interplanetary NanoSpacecraft Pathfinder In Relevant Environment," AIAA 2013-5323, Space 2013, San Diego, CA, September 10-12.

${ }^{15}$ Buchen, E., and DePasquale, D., “2014 Nano/Microsatellite Market Assessment," SpaceWorks Enterprises, January, 2014.

${ }^{16}$ Mann, D. L., "Statement before the Committee on Armed Services Strategic Forces Subcommittee United States Senate on Space Programs," March 12, 2014.

${ }^{17}$ Spaceflight Inc., Retrieved from http://spaceflightservices.com/pricing-plans/, June 1, 2015.

${ }_{18}^{18}$ Savage, D., Discovery Mission Concept Study Selection Statement, NASA HQ Release 93-027, February 11, 1993.

${ }^{19}$ Szabo, J., Hruby, V., "Breakthrough Concepts for Mars Exploration with In-Situ Propellants," Concepts and Approaches for Mars Exploration, Houston, Texas, June 12-14, 2012.

${ }^{20}$ Drake, B. G., "Human Exploration of Mars Design Reference Architecture 5.0,” NASA SP-2009-566, July, 2009.

${ }^{21}$ Mercer, C. R., Oleson, S. R., and Drake, B., "A Combined Solar Electric and Storable Chemical Propulsion Vehicle for Piloted Mars Mission,” AIAA Space 2013, San Diego, CA, September 1-12, 2013. 